\title{
BIOMECÂNICA APLICADA À EDUCAÇÃO FÍSICA: COMPONENTE CURRICULAR NA FORMAÇÃO DE PROFESSORES
}

\author{
BIOMECHANICS APPLIED TO PHYSICAL EDUCATION: \\ CURRICULUM COMPONENT IN TEACHER TRAINING
}

\author{
BIOMECÁNICA APLICADA A LA EDUCACIÓN FÍSICA: \\ COMPONENTE CURRICULAR EN LA FORMACIÓN DOCENTE
}

Cássia Hack*, Celi N. Zülke Taffarel**, Nair Casagrande**

\begin{abstract}
Palavras chave Biomecânica.

Educação Física.

Currículo. Docentes.

Resumo: $O$ estudo investigou a Biomecânica Aplicada à Educação Física (BaEF) na formação de professores. A pesquisa foi realizada na UFBA entre 2012 e 2015, subsidiada na teoria histórico-cultural, teoria pedagógica histórico-crítica e crítica à organização do trabalho pedagógico e à didática. Os procedimentos foram revisão bibliográfica, análise documental, dados empíricos da disciplina de BaEF. Considerando que o conhecimento sobre BaEF é uma regularidade onde atua o professor de EF, concluímos que é imprescindível para a aprendizagem dos conteúdos da cultura corporal.
\end{abstract}

Keywords: Biomechanics. Physical Education. Curriculum. Faculty.
Abstract: The study investigated Biomechanics Applied to Physical Education (BaPE) in teacher training. It was carried out at the Federal University of Bahia (UFBA) in 20122015. It was based on cultural-historical theory, critical-historical pedagogical theory, and criticism of the organization of pedagogical work and didactics. Procedures included literature review, document analysis, and empirical data collection in the BaPE discipline. Considering that knowledge about $\mathrm{BaEF}$ is a regular need for PE teachers, it concludes that it is essential for learning body culture content.

Palabras clave: Biomecánica. Educación Física. Curriculum. Docentes.
Resumen: El estudio investigó la Biomecánica Aplicada a la Educación Física (BaEF) en la formación docente. La investigación se realizó en la UFBA entre 2012 y 2015 , fundamentada en la teoría histórico-cultural, la teoría pedagógica histórico-crítica y en la crítica a la organización del trabajo pedagógico y a la didáctica. Para ello se realizó una revisión bibliográfica, un análisis documental, y se recogieron datos empíricos del módulo de $\mathrm{BaEF}$. En vista de que el conocimiento sobre BaEF es una regularidad donde actúa el profesor de EF, concluimos el mismo es imprescindible para el aprendizaje de los contenidos de la cultura corporal.
*Universidade Federal do Amapá. Macapá, AP, Brasil. E-mail: cassia.hack@gmail.com

**Universidade Federal da Bahia. Salvador, BA, Brasil. E-mail: taffarel@ufba.br

Recebido em: 03-03-2016 Aprovado em: 14-06-2016 (c) (1) () Licence 


\section{APRESENTAÇÃO}

O estudo investiga a trajetória da Biomecânica aplicada à Educação Física (BaEF), no cenário nacional brasileiro, a partir da especificidade da experiência da Universidade Federal da Bahia (UFBA). Investiga o conhecimento reconhecido como clássico da Biomecânica e defende sua inserção nos currículos de formação e na atuação profissional de professores de Educação Física (EF), considerando a necessidade de organização do trabalho pedagógico (COLETIVO DE AUTORES, 1992; ESCOBAR, 1997) e o trato com o conhecimento em espaços formativos dos sistemas educacional, de saúde, de lazer e de treinamento esportivo (UFBA, 2011)1.

As questões orientadoras da investigação nos levaram a recuperar a origem da Biomecânica no Brasil e seu desenvolvimento atual, visível nos trabalhos dos grupos de pesquisa e na exposição de conhecimentos científicos em eventos de duas entidades cientificas: Sociedade Brasileira de Biomecânica (SBB) e Colégio Brasileiro de Ciências do Esporte (CBCE). Este foi confrontado com os resultados da experiência da UFBA, de 2012 a 2015, em que a disciplina Biomecânica Aplicada à Educação Física é obrigatória na formação dos professores de Educação Física.

Os dados advindos desses estudos estão nos permitindo defender a tese sobre a inclusão da disciplina de Biomecânica Aplicada à Educação Física nos currículos de formação de professores de Educação Física.

O objetivo geral do estudo, tendo como campo de investigaçãoa experiência desenvolvida no período de 2012 a 2015 no Curso de EF da UFBA e a origem e desenvolvimento da BaEF no Brasil, foi apresentar subsídios para a inclusão desta disciplina nos currículos de formação de professores de Educação Física, a partir da análise das regularidades, nos campos de trabalho da EF, das exigências quanto ao domínio do conhecimento clássico da Biomecânica para a organização do trabalho pedagógico e o trato com o conhecimento científico.

Este objetivo geral desdobra-se nos seguintes objetivos específicos: a) analisar o desenvolvimento do conhecimento da BaEF no Brasil, considerando estudos anteriores, os grupos de pesquisa e anais de eventos científicos da SBB e do CBCE; b) identificar as regularidades sobre o conhecimento a respeito da BaEF nos campos de trabalho da EF a partir da análise do Projeto Político Pedagógico (PPP) do Curso da UFBA; e c) reconhecer as exigências do domínio do conhecimento clássico da Biomecânica para a organização do trabalho pedagógico na escola.

Realizamos esta análise junto à disciplina "Biomecânica Aplicada à Educação Física (EDCD 75)", inserida no "Módulo dos Fundamentos", articulada e integrada com os "Módulos do Conhecimento Específico da área da cultura corporal" (jogo, luta, ginástica, esporte, malabarismos, etc.), da "Práxis" (prática do ensino e estágio supervisionado) e do "Trabalho Científico" (domínio de teorias do conhecimento e da epistemologia). Esta organização constitui a proposta curricular para a formação de professores de EF, implementada desde 2011 na UFBA (UNIVERSIDADE FEDERAL DA BAHIA, 2011) e que vem sendo investigada em trabalhos de pós-graduandos, conforme pode ser constatado na tese de Morschbacher (2016) que sustenta a necessidade de atitude científica, o que pressupõe o domínio do conhecimento clássico sobre os objetos da Educação Física. 
O método de investigação adotado está subsidiado na teoria histórico-cultural (LEONTIEV, 1977, 1978; MARTINS, 2013), que explica o desenvolvimento da psiquê humana e as relações com a educação escolar; na teoria pedagógica histórico-crítica (SAVIANI, 1989, 2003, 2008; MARSIGLIA, 2011; SAVIANI; DUARTE, 2012), que reconhece como função social da escola elevar a capacidade teórica dos estudantes; e na crítica à organização do trabalho pedagógico à didática (FREITAS, 1995; ESCOBAR, 1997), que indica a relação professores-estudante-conhecimento como central no trabalho pedagógico. Os procedimentos de investigação daí decorrentes implicaram na análise documental e revisão bibliográfica, bem como em procedimentos da pesquisa empírica, na disciplina de BaEF desenvolvida no período de 2012 a 2015 na UFBA.

A exposição e discussão dos resultados estruturam-se conforme segue: elementos da trajetória da BaEF no Brasil, a partir da literatura, de grupos de pesquisa e de eventos científicos; a experiência da UFBA com a disciplina de BaEF; e as considerações finais.

\section{ELEMENTOS DA TRAJETÓRIA DA BIOMECÂNICA APLICADA À EDUCAÇÃO FÍSICA NO BRASIL}

No Brasil, segundo registros históricos, as primeiras propostas curriculares para a criação das Escolas de EF tinham a obrigatoriedade da disciplina Cinesiologia. Segundo Amadio e Serrão (2004), a introdução da Biomecânica nestes cursos teve impulso no Brasil por volta de 1965, quando se concretizava o acordo cultural entre o Brasil e a República Federal da Alemanha.

Um dos importantes registros, conforme estes autores, encontra-se na obra de Maria Lenk, de 1942, intitulada Natação. A autora, que foi um dos ícones da natação brasileira, realizou a análise dos movimentos dos nados visando esclarecer as dúvidas e soluções para melhor êxito dos nadadores. O livro apresenta explicações teóricas a respeito da eficiência dos nados desenvolvidas até aquele momento.

A relevância desta obra, segundo Amadio e Serrão (2004, p. 45), deve-se ao fato de ser o "[...] primeiro livro, escrito em português, que aplica os conceitos da Biomecânica na análise de um movimento esportivo". Para os autores, a análise de Maria Lenk aplica os fundamentos físicos que permitem uma melhor compreensão e resolução das questões técnicas relacionadas às diferentes formas de nado. A autora apresenta fotografias submersas da sequência de movimentos do nado butterfly que permitem detalhada análise do nado, comprovando teorias sistematizadas no livro.

Retomando o percurso histórico da Biomecânica no Brasil, encontramos os registros do convênio Brasil-Alemanha em 1976, com os cursos de Biomecânica na Universidade de São Paulo (USP) e o Curso de Especialização em Biomecânica do Esporte realizado na Universidade Federal de Santa Maria (UFSM) ministrados pelo professor Dr. Hartmut Riehle.

O principal objetivo do curso era a formação de especialistas na área para trabalharem nos cursos de formação de professores em EF e tinha como meta a compreensão dos fenômenos mecânicos relacionados ao movimento corporal humano.

Em 1979, ainda no interior dos acordos Brasil-Alemanha, ocorreu a visita do professor Dr. Wolfgang Baumann, que teve como propósito visitar a USP, a UFSM, a Universidade Federal 
do Rio de Janeiro (UFRJ) e a Universidade Estadual do Rio de Janeiro (UERJ). Seu objetivo era diagnosticar a realidade do desenvolvimento da Biomecânica nestas universidades, estimar possibilidades de projetos a serem realizados, bem como fornecer orientação especializada a fim de serem construídos ou ampliados laboratórios que pudessem desenvolver trabalhos na área.

Conforme Amadio e Serrão (2004), no Brasil, desde os anos de 1980 até a atualidade, a área da Biomecânica, enquanto disciplina no contexto científico-acadêmico, vem passando por um expressivo crescimento e expansão, em especial no seu campo de aplicação.

Atualmente, a área da Biomecânica encontra-se em pleno desenvolvimento. Alguns dados podem ser observados no artigo elaborado por Franciulli et al. (2008). Os autores objetivaram descrever e analisar a produção científica, organizada nas várias edições do Congresso Brasileiro de Biomecânica (CBB) e identificar grupos de pesquisa e programas de pós-graduação stricto sensu, referentes à área da Biomecânica, existentes no País. Destacaram a existência de pesquisadores, grupos de pesquisa e programas de pós-graduação em todas as diferentes regiões do Brasil. Contudo, tal otimismo diminui diante da constatação de que a distribuição regional é intensamente desigual.

Os dados mostram que o número de pesquisadores doutores atuantes em grupos de pesquisa na Região Sudeste do Brasil, até o ano da publicação dos resultados, é consideravelmente maior que a encontrada nas demais regiões. Essa região possui mais da metade dos pesquisadores em Biomecânica, com $67 \%$ de doutores e $58 \%$ de graduados.

Já a Região Sul possui $22 \%$ dos doutores e $27 \%$ dos graduados, tendo assim o dobro de pesquisadores da soma das regiões Norte, Nordeste e Centro-oeste, que somam ao todo $10 \%$ de doutores e $14 \%$ de graduados.

A partir desses dados, observamos que a área da Biomecânica vem se consolidando no Brasil de forma mais intensa desde a década de 1970. No entanto, observamos que sua consolidação e desenvolvimento não alcançou uma forma comum, como uma disciplina acadêmica e na existência de grupos de pesquisa e programas de pós-graduação, nas diferentes regiões do país.

Ao realizarmos um recorte de análise no estado da Bahia, observamos que não houve mudança nos anos recentes, conforme veremos a seguir.

O estado da Bahia, localizado no nordeste do Brasil, é composto por 417 municípios, os quais totalizam uma população de 15 milhões de habitantes. Apresenta atualmente um total de 73 Cursos de EF, ofertados por 25 instituições privadas e sete universidades públicas. Deste total de cursos oferecidos, 43 são particulares e 30 são públicos. Estes estão organizados em 21 cursos de bacharelados e 52 cursos de licenciatura, sendo 62 presenciais e 11 a distância (MINISTÉRIO DA EDUCAÇÃO, 2015).

No interior dessa realidade, destacamos a experiência do Curso de Licenciatura em EF, de caráter ampliado, da Faculdade de Educação (FACED) da UFBA, considerando que é um dos cursos mais antigos da Bahia, cujo processo de criação decorreu durante a década de 1980. Foi criado legalmente no ano de 1987, mas teve seu primeiro ano de funcionamento em 19 de outubro de 1988 (PIRES, 2015) e foi reconhecido pelo Ministério da Educação apenas em 1996. No entanto, a disciplina BaEF foi inserida somente com a reforma curricular implementada em 2011, ou seja, 23 anos depois da criação legal do curso. 
No período da avaliação institucional do curso, pela Comissão do Instituto Nacional de Estudos e Pesquisas Educacionais Anísio Teixeira (INEP), em 2011, foi recomendado pela Comissão de avaliação que a disciplina deixasse de ser obrigatória para ser optativa. Nos opusemos a tal proposição por reconhecer que o conhecimento da BaEF é um conhecimento imprescindível na formação de professores.

Temos que admitir que a produção do conhecimento no campo da Biomecânica é recente no Brasil e vem sendo desenvolvido por diferentes grupos de pesquisa. Em um levantamento realizado nos registros do Conselho Nacional de Desenvolvimento Científico e Tecnológico (CNPq), em 2012, com o objetivo de analisar os grupos de pesquisa cadastrados e ligados à área da Biomecânica, localizados no estado da Bahia, encontramos a existência de nove grupos de pesquisa. Porém, todos eles ligados às áreas de Engenharia, Odontologia, Farmacologia, Saúde Pública, dentre outras.

Não encontramos qualquer grupo de pesquisa ligado à área de EF. Estes dados não apresentaram alterações até o ano de 2015, o que reforçaa disparidade regional de desenvolvimento científico e tecnológico no País. De maneira geral, os dados encontrados não se diferenciaram qualitativa e quantitativamente daqueles apresentados por Franciulli et al. em 2008.

Nesta nova busca, durante o primeiro semestre de 2015, no Diretório de Grupos de Pesquisa do CNPq (CONSELHO NACIONAL DE DESENVOLVIMENTO CIENTÍFICO E TECNOLÓGICO, 2015)², utilizamos o termo de busca "Biomecânica" durante a consulta parametrizada.

Quanto aos filtros, foram utilizados: a) para localização do grupo e tempo de existência do grupo delimitamos por "região", por "Unidade Federativa (UF)", por "instituições", b) para área do conhecimento e setor de aplicação, delimitamos: "Grande área: Ciências da Saúde"; "Predominância da Área: Educação Física"; "Setor de aplicação: todas"; "divisão: todas", c) para formação acadêmica: "todas"; e d) para o campo "bolsistas CNPq ou docentes", delimitamos: "sem marcação específica".

No segundo momento da busca utilizamos os mesmos critérios, porém especificando a área do conhecimento, na qual definimos a "linha de pesquisa dos grupos" como sendo "Área de EF relacionados à Biomecânica".

No filtro em "predominância por grupo" (Quadro 1) foram encontrados 59 grupos na Grande Área do Conhecimento das Ciências da Saúde, vinculados à área da EF, que institucionalmente se concentram localizados nas universidades públicas dos três estados da Região Sul e, no Sudeste, em São Paulo, Rio de Janeiro e Minas Gerais. E, em algumas destas universidades, observamos mais de um grupo de pesquisa na mesma instituição, tal como ocorre na Região Sul, na Universidade Federal do Rio Grande do Sul (UFRGS), Universidade Federal de Santa Catarina (UFSC), Universidade do Estado de Santa Catarina (UDESC), Universidade de Londrina (UEL), Universidade de Maringá (UEM) e na, Região Sudeste, em instituições como a USP, Universidade de Campinas (UNICAMP), Universidade Federal de São Carlos (UFSCar) e a Universidade Estadual Paulista Júlio de Mesquita Filho (UNESP), todas localizadas em São Paulo.

2 CONSELHO NACIONAL DE DESENVOLVIMENTO CIENTíFICO E TECNOLÓGICO. Diretório de Grupos de Pesquisa no Brasil. Disponivel em: <http://lattes.cnpq.br/web/dgp>. Acesso em: 23 mar. 2015. O Diretório de Grupos de Pesquisa no Brasil, do CNPq, pode ser acessado neste referido endereço eletrônico. o Brasil, ndereço nesteferido endereco eletronico. digitalizada (PDF) e podem ser solicitados ;) iplined body has lost power. I 
Nas demais regiões brasileiras isso não ocorre, visto que encontramos alguns grupos esparsos, em diferentes estados, ou no máximo dois grupos em um mesmo estado, tal como no Amazonas, em Goiás e Pernambuco. Este detalhamento pode ser observado no Quadro 1.

Quadro 1 - Quantidade de grupos de pesquisa, registrados no Diretório de Grupos de Pesquisa do CNPq, distribuídos por estado/regiões brasileiras, encontrados a partir do termo de busca "Biomecânica", como "Predominância por Grupo".

\begin{tabular}{|c|c|c|c|c|}
\hline \multicolumn{5}{|c|}{ PREDOMINÂNCIA POR GRUPO } \\
\hline REGIÃO & ESTADO & INSTITUIÇÃO & $\begin{array}{l}\text { GRUPOS POR } \\
\text { ESTADO }\end{array}$ & $\begin{array}{l}\text { TOTAL POR } \\
\text { REGIÃO }\end{array}$ \\
\hline \multirow{2}{*}{$\begin{array}{l}\text { CENTRO- } \\
\text { OESTE }\end{array}$} & DF & UnB & 01 & \multirow{2}{*}{03} \\
\hline & GO & UFG, IFG & 02 & \\
\hline \multirow{2}{*}{ NORDESTE } & $\mathrm{PE}$ & UPE, UNIVASP & 02 & \multirow[b]{2}{*}{03} \\
\hline & SE & UFS & 01 & \\
\hline NORTE & AM & UFAM, UEA & 02 & 02 \\
\hline \multirow{4}{*}{ SUDESTE } & ES & UFES & 01 & \multirow[b]{4}{*}{23} \\
\hline & $M G$ & UFOP, UFMG, UFLA & 03 & \\
\hline & RJ & UFRJ, UERJ, UFF, UGF, CCFEx & 05 & \\
\hline & SP & $\begin{array}{l}\text { USP, UNICAMP, UNESP, UFSCar, } \\
\text { MACKENZIE, UNICASTELO, USTJ }\end{array}$ & 14 & \\
\hline \multirow{3}{*}{ SUL } & PR & UEM, UTFPR, UEL, FACBRASIL & 07 & \multirow[b]{3}{*}{28} \\
\hline & SC & UFSC, UDESC, UNISUL & 08 & \\
\hline & RG & $\begin{array}{c}\text { UFRGS, UFPel, UFSM, NIPAMPA, PUCRS, } \\
\text { IBTEC, UNISINOS }\end{array}$ & 13 & \\
\hline \multicolumn{4}{|c|}{ TOTAL NO BRASIL } & 59 \\
\hline
\end{tabular}

Fonte: Dados do Diretório de Grupos de Pesquisa CNPq (2015) sistematizados pelas autoras.

Relacionada à "linha de pesquisa dos grupos" (Quadro 2, na próxima página), com 0 recorte do termo "Biomecânica", encontramos 81 grupos. Contudo, ampliam-se as grandes áreas do conhecimento para as Ciências Agrárias (um no Sudeste), as Ciências Biológicas (um no Centro-Oeste, dois no Sudeste e um no Sul), as Ciências Exatas e da Terra (um no Nordeste) e as Engenharias (um no Centro Oeste, um no Nordeste, três no Sudeste e um no Sul). E no que se refere às Ciências da Saúde, além da área de EF, ampliam-se para as áreas da Farmácia, Fisioterapia, Nutrição e Saúde Coletiva.

Analisamos, ainda, anais de eventos de duas entidades científicas brasileiras: a Sociedade Brasileira de Biomecânica (SBB) e o Colégio Brasileiro de Ciências do Esporte $(\mathrm{CBCE})$, objetivando identificar trabalhos e atividades na programação que tratassem 0 conhecimento da Biomecânica aplicado à EF Escolar (EFE) e formação de professores. A escolha desses eventos deveu-se pela atualidade (última edição em 2015) e pela relevância para a Educação Física das entidades científicas que os promoveram.

O evento organizado pela SBB, o XVI Congresso Brasileiro de Biomecânica e VI Simpósio em Neuromecânica Aplicada, realizado de 6 a 9 de maio de 2015, em Florianópolis/ SC, tem caráter internacional, é bianual, e destinado à comunidade acadêmica em geral que atua nas áreas de Educação Física, Fisioterapia, Medicina, Neurociências e Engenharia Biomédica. Observamos no cômputo total da programação as seguintes atividades: oito workshops, 19 
palestras, uma conferência, 28 temas livres, quatro mesas-redondas, 275 pôsteres publicados nos anais, totalizando 335 atividades gerais (SOCIEDADE BRASILEIRA DE BIOMECÂNICA, 2015).

Quadro 2 - Quantidade de grupos de pesquisa, registrados no Diretório de Grupos de Pesquisa do CNPq, distribuídos por estado/regiões brasileiras, encontrados a partir do termo de busca "Biomecânica", apenas como "linha de pesquisa".

\begin{tabular}{|c|c|c|c|}
\hline \multicolumn{4}{|c|}{ RELACIONADA À LINHA DE PESQUISA } \\
\hline REGIÃO & QUANTIDADE DE GRUPOS & ESTADO & TOTAL POR REGIÃO \\
\hline \multirow{2}{*}{ CENTRO-OESTE } & 01 & DF & \multirow[b]{2}{*}{7} \\
\hline & 06 & GO & \\
\hline \multirow{6}{*}{ NORDESTE } & 01 & BA & \multirow{6}{*}{9} \\
\hline & 02 & $\mathrm{RN}$ & \\
\hline & 01 & PB & \\
\hline & 03 & $\mathrm{PE}$ & \\
\hline & 01 & $\mathrm{PI}$ & \\
\hline & 01 & SE & \\
\hline NORTE & 02 & AM & 2 \\
\hline \multirow{3}{*}{ SUDESTE } & 07 & MG & \multirow{3}{*}{30} \\
\hline & 05 & RJ & \\
\hline & 18 & SP & \\
\hline \multirow{3}{*}{ SUL } & 09 & PR & \multirow{3}{*}{33} \\
\hline & 08 & SC & \\
\hline & 16 & RG & \\
\hline & & TOTAL NO BRASIL & 81 \\
\hline
\end{tabular}

Fonte: Dados do Diretório de Grupos de Pesquisa CNPq (2015) sistematizados pelas autoras.

Desse total, identificamos quatro possíveis aproximações com a temática da BaEF ligadas à formação de professores, sendo dois pôsteres [148 e 162], um workshop ["Ensino de Biomecânica: Como estamos ensinando e aprendendo Biomecânica?"] e uma mesa ["Fronteiras do conhecimento da Biomecânica"], ou seja, neste universo pouco mais de $1 \%$ tratou, de alguma forma, da relação da Biomecânica aplicada à EFE e à formação de professores.

Esse dado não gera demasiada surpresa, tendo em vista que desde a apresentação do evento identifica-se uma distância entre esta relação, quando há o registro nos anais de que a proposta do evento aborda temas relacionados à "Biomecânica Clínica e da Reabilitação, Biomecânica do Esporte, Biomecânica Neuromuscular, Bioengenharia, Instrumentação/Novas Tecnologias e Equilíbrio, Marcha eLocomoção" (SOCIEDADEBRASILEIRADEBIOMECÂNICA, 2015, p.3).

É certo que compõe a SBB uma amplitude de áreas de estudo de diversos interesses, tendo em vista a face multidisciplinar da própria Biomecânica, necessitando ainda desenvolver laços interdisciplinares com a formação de professores de EF e, consequentemente, os trabalhos de Biomecânica na EF Escolar. Registra-se que há uma quantidade considerável de trabalhos elaborados a partir de experiências esportivas, de análise do movimento, prevenção e reabilitação que também compõem os campos de atuação do professor de Educação Física. 
O evento do CBCE XIX Congresso Brasileiro de Ciências do Esporte - CONBRACE e VI Congresso Internacional de Ciências do Esporte - CONICE - Territorialidade e diversidade regional no Brasil e América Latina: suas conexões com a Educação Física e Ciências do Esporte ocorreu de 8 a 13 de setembro em Vitória/ES. Reuniu "pesquisadores e estudantes, brasileiros e estrangeiros, interessados nessa área de estudos, os quais têm encontrado [...] oportunidades de intercâmbio acadêmico e estabelecimento de novos circuitos de trocas e investimentos em projetos científicos comuns" (COLÉGIO BRASILEIRO DE CIÊNCIAS DO ESPORTE, 2015, p.5).

Da programação geral, constante na Agenda do CONBRACE (COLÉGIO BRASILEIRO DE CIÊNCIAS DO ESPORTE, 2015), foram apreendidas três conferências, três mesas gerais, 11 mesas internas aos Grupos de Trabalho Temáticos (GTTs), duas assembleias gerais, um painel cultural, sete reuniões institucionais, um Fórum da Pós-Graduação, uma Exposição Histórica, uma sessão de lançamentos de livro, Sala de Imagem com mostra permanente, cinco sessões de apresentações orais de cada um dos 13 GTTs (288 comunicações orais), duas sessões de pôsteres (374 pôsteres), totalizando 693 possibilidades.

Dos títulos da programação geral não constatou-se nada relacionado à Biomecânica aplicada à Educação Física, nem tampouco na busca nos anais on line do evento em que pôdese acessar os 662 trabalhos nos formatos de comunicação oral e pôster.

A partir da constatação de que na edição de 2015 do CONBRACE nenhum professor ou estudante no campo da EF apresentou trabalho relacionado à Biomecânica e nem a entidade CBCE propôs tal atividade, e que aproximadamente 1\% da edição 2015 do CBB tratou da Biomecânica aplicada à EF, a hipótese que levantamos é que a produção de conhecimento, neste recorte, não chega até o CBB e CONBRACE, por distintos fatores, tais como, por ser diminuta; por não ter parte nos currículos de formação de professores de EF; por não estar no chão da escola; ou por não ter a devida valorização (tanto na formação quanto no exercício profissional) e ou estar deveras distanciada dos centros de excelência da Biomecânica.

Diante desta realidade brasileira, frente à producão, socialização do conhecimento e a distribuicão de grupos de pesquisa na área da $\mathrm{BaEF}$, apresentamos a seguir a experiência da UFBA.

\section{A EXPERIÊNCIA DA UFBA COM A DISCIPLINA DE BIOMECÂNICA APLICADA À EDUCAÇÃO FÍSICA}

Na UFBA, a disciplina BaEF passou a ser disponibilizada como componente curricular no ano de 2012, após a reconceptualização curricular aprovada institucionalmente em 2011.

Na constituição e desenvolvimento da disciplina, foram implementados procedimentos de pesquisa, ao longo do período de 2012 a 2015 (TAFFAREL, CASAGRANDE, AMORIM, 2012; TAFFAREL, CASAGRANDE, JESUS, 2013; HACK et al., 2015)3. Assim, foram realizadas: a) Revisão da literatura para reconhecer o já realizado e o conhecimento clássico da BaEF; b) Análise do conteúdo de programas de disciplinas de cursos no Brasil (MORSCHBACHER,

3 TAFFAREL, C. N. Z.; CASAGRANDE, N.; AMORIM, R. B. Relatório Técnico-Científico da Disciplina EDCD75 - Biomecânica aplicada à Educação Física-UFBA -2012.1. Salvador/BA: UFBA, 2012. TAFFAREL, C. N. Z.; CASAGRANDE, N.; JESUS, E. S. de. Relatório TécnicoCientífico da Disciplina EDCD75 - Biomecânica aplicada à Educação Física - UFBA - 2013.1. Salvador/BA:UFBA, 2013.; HACK, C. et al. 
2012); c) Análise da experiência desenvolvida durante quatro anos (2012-2015) na UFBA para instituir e desenvolver a disciplina BaEF, no Curso de Licenciatura em EF na qual se insere a experiência para instalar um laboratório de BaEF.

A disciplina de BaEF, no Curso de Licenciatura em EF de Caráter Ampliado na FACED/UFBA, compõe o Módulo dos Fundamentos do currículo. O currículo por sua vez, está estruturado em quatro módulos: a) "Módulo dos fundamentos"; b) "Módulo dos conteúdos específicos da cultura corporal"; c) "Módulo da práxis", que se desdobra em prática do ensino e estágio supervisionado e; d) "Módulo do trabalho científico" (UNIVERSIDADE FEDERAL DA BAHIA, 2011).

Sobre o perfil de formação e atuação do profissional, professor de EF da UFBA, os estudos indicaram, a partir das relações Trabalho-Educação-EF, que a característica fundante do exercício profissional é a docência. $O$ exercício da docência, em campos de trabalho que se expandem, implica conduzir processos de ensino e aprendizagem, gestão e administração destes; tanto em aulas, sessões, como em instituições ou nas políticas públicas, e na produção do conhecimento científico sobre o objeto específico, a saber, a cultura corporal.

Para formar tal perfil é imprescindível o domínio do conhecimento científico elaborado historicamente. Deste universo são selecionados aqueles que terão o tratamento pedagógico essencial na educação formal, providas as condições objetivas para sua assimilação a partir do processo histórico de sua produção.

Os campos de trabalho indicados pelo PPP da UFBA são organizados em sistemas dos quais destacamos: sistema educacional; sistema de saúde; sistema de lazer; sistema esportivo; sistema das políticas públicas em geral. Analisando estes sistemas, através da análise dos documentos públicos, sobre diretrizes e forma de ingresso nos sistemas, constatamos que todos exigem conhecimentos sobre Educação Física e todos exigem habilidades e competências para tratar de tal conhecimento.

Identificamos, ainda, como regularidade no conhecimento a ser abordado, a indicação dos conteúdos da cultura corporal como esporte, ginástica, dança, jogos, lutas, entre outros. Identificamos, por fim, como regularidade, que os conteúdos da Educação Física têm como subsídios os conhecimentos clássicos relacionados à Biomecânica Aplicada à Educação Física, quando a atividade está relacionada à marcha, ao andar, trotar, correr, lançar, arremessar, saltar, rolar, girar, balançar, embalar, entre outras atividades.

A disciplina de BaEF, na UFBA, levou em consideração as indicações destas regularidades e foi desenvolvida a partir da ementa que propõe como objetivos estudos sobre: a) os fundamentos da atividade humana (gênese filogenética e ontogenética) e, em especial, os fundamentos da cultura corporal à luz da teoria histórico-cultural; b) o conhecimento clássico da Biomecânica e sua aplicação à Educação Física, o histórico da Biomecânica, as bases biológicas e mecânicas da Biomecânica, conceitos fundamentais, princípios e terminologia da Biomecânica, a Cinética e a Cinemática; c) anatomia funcional do corpo humano à luz da teoria histórico-cultural; d) as bases e fundamentos da EF em diferentes sistemas de atuação do professor, a partir das contribuições da BaEF; e) as bases da produção do conhecimento sobre a BaEF no trato de seu conteúdo específico, a cultura corporal.

O desenvolvimento desses conteúdos deu-se a partir de aulas com explanações teóricas, leituras orientadas, acesso a bancos de dados, elaboração de fichamentos e resumos 
analíticos, trabalhos em grupos acompanhados, seminários interativos, experimentações (incluindo curso intensivo com especialista) e aplicações (com a própria turma, em escola pública e comunidade através de aulas e palestra). Alguns procedimentos básicos que compõem a disciplina permitiram articular graduação e pós-graduação, bem como o ensinopesquisa e extensão.

Outro eixo central do currículo do curso de EF da UFBA, identificado na análise do Projeto Político Pedagógico do curso é a "elevação do pensamento científico-teórico dos estudantes" acerca da EF, cujo objeto é a cultura corporal e cujos campos de atuação profissional expandemse das políticas educacionais, de saúde, lazer e treino esportivo de alto rendimento.

O desenvolvimento do pensamento científico-teórico exige que o professor realize uma prática pedagógica que permita aos estudantes se apropriarem de instrumentos de pensamento para o trabalho intelectual, tais como a análise, a síntese e a comparação; o raciocínio indutivo, dedutivo e analógico; a abstração, a generalização e a concreção; a ideia da causalidade, 0 pensamento crítico e a conceituação; e que se apropriem de instrumentais que ampliam a capacidade humana de perceber o que está para além de si.

Considerando a complexa atividade que constitui o pensamento, o professor deve abordar o trabalho mental na unidade de todos esses processos, tendo presente que ele não é apenas um processo psíquico pelo qual o indivíduo obtém o conhecimento generalizado, senão que é ele que concretiza a possibilidade de conhecer e conceber coisas novas.

É necessário, todavia, saber que o trabalho mental que põe de manifesto as relações de causa e efeito adquire, ao mesmo tempo, o caráter de pensamento crítico o qual sempre reflete a orientação que segue a personalidade do estudante, a posição que ele assume e sua atitude valorativa frente aos fenômenos em estudo.

O pensamento crítico constitui uma prova das ações, resoluções, criações e ideias à luz de determinadas teorias, leis, regras, princípios ou normas e, também, da sua correspondência com a realidade.

Shardakov (1978) assinala cinco condições para que se desenvolva essa mentalidade crítica: a) possuir os conhecimentos necessários na esfera em que a atividade mental crítica deverá ser desenvolvida, uma vez que não pode se analisar criticamente aquilo sobre o qual não há dados suficientes; b) estar acostumado a comprovar qualquer resolução, ação ou juízo emitido antes de considerá-los acertados; c) relacionar com a realidade as regras, as leis, as normas ou teorias correspondentes, o processo e o resultado da solução, a ação ou juízo emitido; d) possuir o suficiente nível de desenvolvimento no que diz respeito à construção dos raciocínios lógicos; e) ter suficientemente desenvolvida a personalidade: as opiniões, as convicções, os ideais e a independência na forma de atuar.

Quaisquer tarefas intelectuais requerem o conjunto dessas habilidades discriminadas, assim como a leitura e a elaboração de textos. Por isso o professor deve abandonara comunicação verbal como forma padrão para tratar o conhecimento e substituí-la por procedimentos que tenham a prática do estudante como atividade principal, tais como oficinas, práticas de campo, estudo prático em laboratórios, pesquisa didática, pesquisa matricial, seminários, debates e outras dinâmicas de discussão organizadas com autodeterminação pelos próprios estudantes, elaboração de artigos, resumos, resenhas, monografias e outros trabalhos científicos. Quaisquer tarefas requerem o domínio de conhecimentos clássicos, sem os quais compromete-se a 
capacidade teórica. Neste sentido é que defendemos a consideração dos conteúdos clássicos da BaEF no trabalho pedagógico dos professores de Educação Física.

Este conhecimento clássico, sob a base desta teoria histórico-cultural, na organização da disciplina BaEF, na UFBA, foi estruturado em três blocos:

a) O histórico do desenvolvimento do conhecimento reconhecido como conhecimento da Biomecânica; a transformação deste conhecimento em conhecimento disciplinar; as disciplinas acadêmicas que aplicam o conhecimento da Biomecânica e a aplicação deste conhecimento na área da EF, incluindo aqui a inserção desta área de conhecimento nas instituições de ensino superior; a criação de laboratórios; o desenvolvimento de pesquisas; as disciplinas acadêmicas nos cursos (FREITAS, 1995);

b) OsFundamentos Básicos da Biomecânica ea Análise do Movimento Humano: os fundamentos do Movimento Humano; a Biomecânica básica; terminologia; considerações esqueléticas, musculares, neurológicas e anatomia funcional; análise mecânica do movimento humano a partir da Cinética e da Cinemática; aplicação dos princípios da Biomecânica à cultura corporal, à EF, aos Esportes. Destaca-se o conteúdo sobre a marcha humana (HALL, 2009; FRACCAROLI, 1981; HAMIL, KNUTZEN, 2012; HAY, 1981; McGINNIS, 2002);

c) Análise da Produção do Conhecimento da área da Biomecânica e suas aplicações, em especial na EF. As dissertações e teses no banco de dados da Capes; a inserção no banco de dados do Diretório de Grupos de Pesquisa do CNPq e demais indexadores do conhecimento produzido; periódicos da área e eventos científicos (AMADIO, SERRÃO, 2004).

Em trabalhos que desenvolveram a análise dos cursos de EF constatamos as contradições referentes à negação dos conhecimentos quando a instituição mantém cursos fragmentados de graduação: licenciatura e bacharelado (MORSCHBACHER, 2012). Este conhecimento clássico da Biomecânica não é tratado nas licenciaturas, visto que não é oferecido nos cursos de licenciatura mas somente nos de bacharelado.

Por fim, a análise de quatro anos de trabalho com a área de conhecimento da BaEF na UFBA, no permite afirmar, pelas evidências que:

a) A necessidade de conhecimentos básicos sobre BaEF é uma regularidade nos campos de trabalho, em especial nos sistemas em que atua o professor de EF. Ou seja, para a aprendizagem dos conteúdos da cultura corporal, para o treino de modalidades esportivas, para a adaptação em circunstâncias específicas (por exemplo, pessoas com deficiências, ou diminuição das capacidades físicas decorrentes do passar dos anos), o conhecimento básico da Biomecânica é imprescindível. Sem ele não se explicam as forças internas e externas que agem sobre o indivíduo e sua capacidade de realizar atividades no campo da cultura corporal.

b) Constatamos ainda que o conhecimento é produzido hegemonicamente com base na abordagem positivista de ciência (TRIVIÑOS, 1987; PEIXOTO, MORSCHBACHER, TAFFAREL, 2015), fazendo-se mister abordagens em outras matrizes, como o materialismo histórico dialético (MARX, 2008) e a teoria histórico cultural (LEONTIEV, 1977, 1978), para explicar a atividade humana e a cultura corporal (TAFFAREL, ESCOBAR, s/d) no interior dos modos de produção da vida. Considerando a experiência da UFBA e a revisão da literatura 
podemos afirmar que o interesse acadêmico para investigar a Biomecânica na formação dos professores de EF ainda é pequeno e que o conhecimento clássico da Biomecânica vem sendo produzido, predominantemente, a partir da abordagem do positivismo filosófico (TRIVIÑOS, 1987).

c) Constatamos ainda que não existe a disciplina de BaEF na maioria dos currículos dos cursos de EF da Bahia, assim como não existem laboratórios de BaEF e, muito menos, grupos de pesquisa nesta área específica na Bahia e nem na maioria dos estados nordestinos.

d) A organização do trabalho pedagógico voltado para elevar a capacidade teórica dos estudantes exige do professor o trato com o conhecimento clássico que explica cientificamente a ação humana. Isto significa que a Educação Física deve ser explicada e exercitada pedagogicamente sob as referências clássicas da Biomecânica, considerandose que a BaEF explica cientificamente as possibilidades e limites das atividades corporais levando em conta subsídios filogenéticos e ontogenéticos, ontológicos e históricos.

\section{CONSIDERAÇÕES FINAIS}

Os resultados do estudo evidenciam que a base do conhecimento da BaEF é uma regularidade presente, e necessária, para o trato do conhecimento da EF, na organização do trabalho pedagógico do professor de EF nos diferentes sistemas de atuação deste profissional, seja na escola ou para além dela.

Com base nas constatações e discussões teóricas dos resultados, e frente às necessidades e possibilidades, recomendamos: a) que a política de desenvolvimento científico da EF/Ciência do Esporte contemple incentivos para o desenvolvimento desta área do conhecimento científico, distribuídos de forma ampla entre as diferentes regiões do País; b) que isto seja realizado com ampliação das abordagens científicas, em especial o materialismo histórico dialético e a teoria histórica cultural na produção do conhecimento sobre cultura corporal; c) que a disciplina BaEF possa ser garantida na formação acadêmica de todos os professores em formação inicial ou continuada desta área, independentemente do seu campo de atuação, considerando-se que este conhecimento é fundamental para sua prática profissional; d) que o trato com o conhecimento da BaEF nos cursos de formação de professores privilegiem as relações e nexos entre este conhecimento clássico, o desenvolvimento da psique humana e a organização do trabalho pedagógico.

A experiência desenvolvida na UFBA, na qual a disciplina compõe o "Módulo de fundamentos", foi introduzida de maneira articulada aos módulos que tratam de "conteúdos específicos da cultura corporal"; ao "módulo da práxis" que trata da prática do ensino e dos estágios supervisionados; e ao "módulo do trabalho científico".

Esse processo permitiu que esse conhecimento clássico fosse tratado cientificamente, na formação acadêmica e no exercício da profissão, desenvolvendo a atitude científica do professor de EF. Esta forma, articulada e inserida na realidade social, na qual o professor em formação desempenhou sua ação profissional em diversificados campos de trabalho, enquanto espaços formativos, evidenciou a necessidade do conhecimento clássico da Biomecânica. 


\section{REFERÊNCIAS}

AMADIO, Alberto Carlos; SERRÃO, Júlio Cerca. Biomecânica: Trajetória e consolidação de uma disciplina acadêmica. Revista Paulista de Educação Física, v. 18, p. 45-54, ago. 2004.

COLÉGIO BRASILEIRO DE CIÊNCIAS DO ESPORTE. Agenda do CONBRACE 2015. Vitória/ ES: CBCE, 2015. Disponível em: <http://www.conbrace.org.br/sites/default/files/artigos/arquivos/ agenda.pdf>. Acesso em: 26 jan. 2016.

COLÉGIO BRASILEIRO DE CIÊNCIAS DO ESPORTE. In: CONBRACE, 19; CONICE, 6. Anais .... Vitória, CBCE, 2015. Disponível em: <http://congressos.cbce.org.br/index.php/ conbrace2015/6conice>. Acesso em: 26 jan. 2016.

COLETIVO DE AUTORES. Metodologia do Ensino de Educação Física. São Paulo: Cortez, 1992.

ESCOBAR, Micheli Ortega. Transformação da didática: construção da teoria pedagógica como categorias da prática pedagógica - experiência na disciplina escolar Educação Física. 1997. 199 f. Tese (Doutorado em Educação) - Faculdade de Educação, Universidade Estadual de Campinas, Campinas. 1997.

FRANCIULLI, Patrícia et al. A Pesquisa em Biomecânica no Brasil: Grupos de Pesquisa, PósGraduação e Congressos Brasileiros de Biomecânica. Revista Brasileira de Biomecânica, v.9, n. 16, p. 27-32, maio 2008.

FRACCAROLI, José Luiz. Biomecânica: análise dos movimentos. São Paulo: Manole, 1977.

FREITAS, Luiz Carlos. Crítica a Didática e a organização do Trabalho Pedagógico. Campinas: Papirus, 1995.

HACK, Cássia; TAFFAREL, Celi Nelza Zülke; CASAGRANDE, Nair. Biomecânica aplicada à Educação Física e formação de professores: realidade, necessidades e possibilidades. In: CONGRESSO BRASILEIRO DE BIOMECÂNICA VI SIMPÓSIO EM NEUROMECÂNICA APLICADA. Anais... Florianópolis: UFSC: UDESC, 2015. p. 256.

HALL, Susan J. Biomecânica Básica. 5. ed. São Paulo: Manole, 2009.

HAMILL, Joseph; KNUTZEN, Kathleen M. Bases Biomecânicas do Movimento Humano. 3. ed. São Paulo: Manole, 2012.

HAY, James G. Biomecânica das Técnicas Desportivas. Rio de Janeiro: Interamericana, 1981.

LEONTIEV, Alexis. O homem e a Cultura, In: ADAM; Y. et al. Desporto e desenvolvimento humano. Porto: Seara Nova, 1977. p. 261-284.

LEONTIEV, Alexis N. Atividade, consciência e personalidade. Buenos Aires: Ciência del Hombre, 1978.

MARTINS, Ligia Márcia. 0 desenvolvimento do psiquismo e a Educação Escolar: contribuições à luz da psicologia cultural e da pedagogia histórico-crítica. Campinas: Autores Associados, 2013.

MARSIGLIA, Ana Carolina Galvão. Pedagogia Histórico-Crítica: 30 anos. Campinas, SP: Autores Associados, 2011.

MARX, Karl. Contribuição à crítica da economia política. São Paulo: Expressão Popular, 2008.

McGINNIS, Peter M. Biomecânica do Esporte e Exercício. Porto Alegre: Artmed, 2002. MINISTÉRIO DA EDUCAÇÃO. Cadastro e-MEC de Instituições e Cursos de Educação Superior. Disponível em <http://emec.mec.gov.br/>. Acesso em: 3 jun. 2015. 
MORSCHBACHER, Márcia. Reformas curriculares e a formação do (novo) trabalhador em Educação Física: a subsunção da formação à lógica privada/mercantil. 2012. 245f. Dissertação (Mestrado em Educação Física) - Escola Superior de Educação Física, Universidade Federal de Pelotas, Pelotas, 2012.

MORSCHBACHER, Márcia. Formação de professores: proposições para a formação para o trabalho científico na licenciatura em Educação Física. 2016. 363 f. Tese (Doutorado em Educação) - Faculdade de Educação, Universidade Federal da Bahia, Salvador, 2016.

PEIXOTO, Elza; MORSCHBACHER, Márcia; TAFFAREL, Celi Nelza Zülke. A formação para o trabalho cientifico do professor de Educação Física. Maceió: EDUFAL, 2015.

PIRES, Roberto Gondim. Historia da Educação Física na Bahia: o percurso da formação profissional. Disponível em: <http://www2.faced.ufu.br/colubhe06/anais/ arquivos/178RobertoGondimPires.pdf>. Acesso em: 29 out. 2015.

SAVIANI, Dermeval. Educação: do Senso Comum à Consciência Filosófica. 9. ed. São Paulo: Autores Associados, 1989.

SAVIANI, Dermeval. Escola e Democracia. 36. ed. São Paulo: Autores Associados, 2003.

SAVIANI, Dermeval. Pedagogia Histórico-Critica: Primeiras Aproximações. Campinas: Autores Associados, 2008.

SAVIANI, Dermeval; DUARTE, Newton. Pedagogia Histórico-Critica e Luta de Classe. São Paulo: Autores Associados, 2012.

SOCIEDADE BRASILEIRA DE BIOMECÂNICA. Anais XVI Congresso Brasileiro de Biomecânica VI Simpósio em Neuromecânica aplicada. Florianópolis: Sociedade Brasileira de Biomecânica, 2015.

SHARDAKOV, Mikhail Nikalaevich. Desarrollo del pensamiento en el escolar. La Habana: Libros para la Educación, 1978.

TAFFAREL, Celi Nelza Zülke; ESCOBAR, Michele Ortega. Cultura Corporal e os dualismos necessários a ordem do capital. Disponível em: <http://www.rascunhodigital.faced. ufba.br/ver. php?idtexto=277>. Acesso em: 22 fev. 2015.

TRIVIÑOS, Augusto Nibaldo S. Introdução à pesquisa em ciências sociais. São Paulo: Atlas, 1987.

Agradecimentos: Agradecemos ao apoio de: Prof. Dr. Marcus Tartaruga, UNICENTRO; Prof. Dr. Jefferson Fagundes Loss, UFRGS e da Universidade Federal da Bahia (UFBA). 